\title{
Study on the Geometrical Properties of Brown Rice on Shape Factors
}

\author{
Xiao Feng Ning ${ }^{1}$, Tae Hwan Kang ${ }^{2}$, Oui Woung $\mathrm{Kim}^{3}$, Chung Su $\mathrm{Han}^{1}$ * \\ ${ }^{1}$ Dept. of Biosystems Engineering, Chungbuk National University, Chung-ju, Korea, ${ }^{2}$ Dept. of Bio-Industrial Mechanic \\ Engineering, Kong-Ju National University, Kong-ju, Korea, ${ }^{3}$ Korea Food Research Institute, Sungnam, Korea
}

Received: March $30^{\text {th }}, 2012$; Revised: April 28 ${ }^{\text {th }}, 2012$; Accepted: April $30^{\text {th }}, 2012$

\section{Abstract}

Purpose: This study was conducted to investigate the optimal sorting factors in establishing an efficient sorting technology for brown rice. Methods: The brown rice varieties used in this study were Il Pum, Chu Cheong, Dong Jin, Un Gwang, Nam Pyeong, and Dae An. These were classified into whole grain, unriped grain, and green dead rice. The shape factors were analyzed based on length, width and thickness of the grains. Results: The results revealed that the maximum length among whole grain, unriped grain, and green dead rice was observed in Dae An variety while Chu Cheong variety showed the minimum. Further more, Il Pum brown rice showed the maximum width while Dong Jin variety showed the minimum. In the case of thickness, the maximum was observed in Un Gwang variety and that of the minimum among Nam Pyeong variety for both whole grain and unriped grain. Conclusions: The length and width can be used as determinants in sorting factors of whole grain and green dead rice, and the thickness can be considered as optimum sorting factor of whole grain and unriped grain.

Keywords: Brown rice, Shape factors, Sorting factors, Length, Width, Thickness

\section{Introduction}

Breeding and selection of rice varieties are very important, steps in nice cultivation of suitable lands, because variety contribute to the productivity by $60 \sim$ $70 \%$ (Yoon et al., 2005). Especially, after cultivation of Tong Il-type rice in 1970s, the rice industry became very stable with rice production reaching self-sufficiency status in Korea. Later however, a interest shifted from Tong Il rice to Japonica rice and the breeding aim also turned increasing production into improving quality with consumer demands for high quality rice in 1980 1990s. As a result of the improvement of rice variety and development of culture techniques, Korean rice production reached 5263 kilotons in the 1999s. However, rice imports according to MMA (Minimum Market Access) increased in the following years given: 2005s-22.5 kilotons $\rightarrow$

\footnotetext{
*Comesponding author: Chung Su Han

Tel: +82-43-261-2580; Fax: +82-43-271-2580

E-mail: hansu@chungbuk.ac.kr
}

2006s-24.6 kilotons $\rightarrow 2007 \mathrm{~s}-26.6$ kilotons $\rightarrow$ 2008s28.7 kilotons $\rightarrow$ 2009s-79.8 kilotons $\rightarrow$ 2010s-98.1 kilotons $\rightarrow$ 2011-104.2 kilotons) and rice consumption per head (2002s: $87 \mathrm{~kg} \rightarrow 2004 \mathrm{~s}: 82 \mathrm{~kg} \rightarrow 2006 \mathrm{s:}: 78.8 \mathrm{~kg} \rightarrow 2007 \mathrm{s:}$ $76.9 \mathrm{~kg} \rightarrow 2009 \mathrm{~s}: 74.0 \mathrm{~kg} \rightarrow 2010 \mathrm{~s}: 72.8 \mathrm{~kg} \rightarrow 2011 \mathrm{~s}: 71.2$ $\mathrm{kg}$ ) decreased by $1.5 \mathrm{~kg}$ yearly. thus rice stock lead to an excess of 144 kilotons (Choung et al., 2008). In order to improve the quality of rice, the rice industry began efforts to diversify and develop functionality further. Therefore, there is need for production of high quality rice with the comsumer demand and change in international market (Han et al., 2001). In addition, many studies of rice have been carried out, such as, breeding of new rice varieties, growth characteristics (Lee, 2010), pest resistance (Kawata et al., 1992; Bughio and Wilkins, 2004), milling characteristics (Kim et al., 2009), and sensory characteristics (Park et al., 2011).

On the other hand, the quality and production of rice are closely related to variety and grown environment, harvesting, drying, storage and milling (Kim et al., 2001). 
With changes in dietary patterns and improved living standards, various varieties of the rice including Il Pum, Chu Cheong, Dong Jin, Un Gwang, Nam Pyeong, and Dae An, which have good taste and high productivity, are widely cultivated in Korea.

However, in the initial RPC (Rice Processing Complex) step of rice processing, it may lead the energy loss and the degradation of rice quality resulting from the difference of rice shape and characteristics of the new rice varieties. Thus, in the future, it is necessary to develop the RPC processing model, which is able to save energy and production of high quality rice.

Subsequent to this, basic data for sorting rice according to the rice shape factor were required. However, limited attention has been given to the study of the geometric characteristics of brown rice.

In consideration of these issues, the present study was conducted to optimize the sorting factors and the geometrical properties of brown rice, and establish the efficient sorting technology.

\section{Materials and Methods}

\section{Materials}

The brown rice varieties used in this study were Il Pum,
Chu Cheong, Dong Jin, Un Gwang, Nam Pyeong, and Dae An. They were harvested in 2009. The initial moisture content of the brown rice were $21.3 \%$ (w.b) (Il Pum), 22.0\% (Chu Cheong), 19.4\% (Dong Jin), 18.3\% (Un Gwang), 19.0\% (Nam Pyeong), and 19.0\% (Dae An), respectively. The rough rice was dried at a rate of $1 \%$ decrease in moisture content, and until the final moisture content reached 13\% using a hot air dryer. The dried rough rice was then processed into brown rice for the experiment. There is no information about the number of samples. Are the length, width and thickness the average values? Mention about it.

\section{Experimental methods}

The rough rice was hulled by a rice husker (FCEK, Yamamoto, Japan) according to their moisture content, and then classified as whole grain, unriped grain, and green dead rice using a $1.75 \mathrm{~mm}$ sieve separator. The number of grain samples were over the 1,000 kernels. The length and width of brown rice were measured by a grain discriminator (RN-500, Kett, Korea), and the thickness of brown rice was measured by a thickness gauge (G, PEACOCK, Japan) as shown in Figure 1. The measured data of length, width and thickness of brown rice calculated the average values.

The moisture content of brown rice was measured

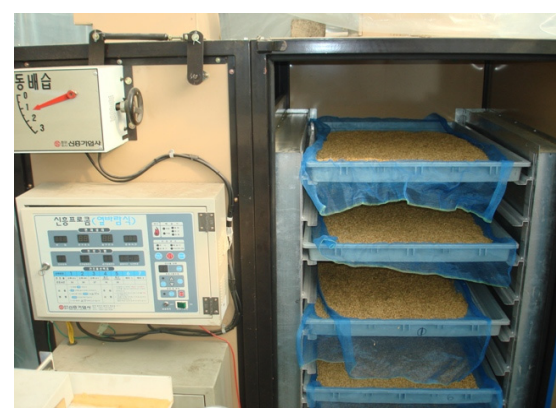

(a) Rough rice drying

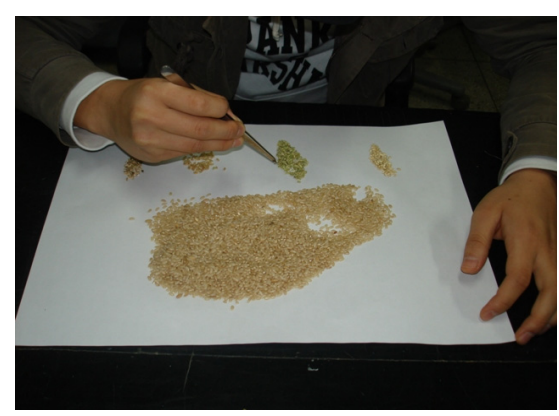

(d) Sorting by hand

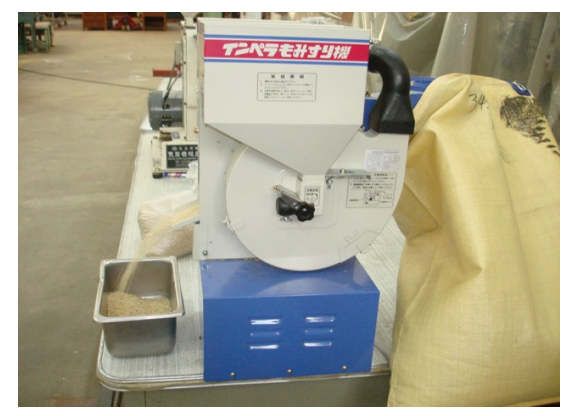

(b) Rough rice hulling

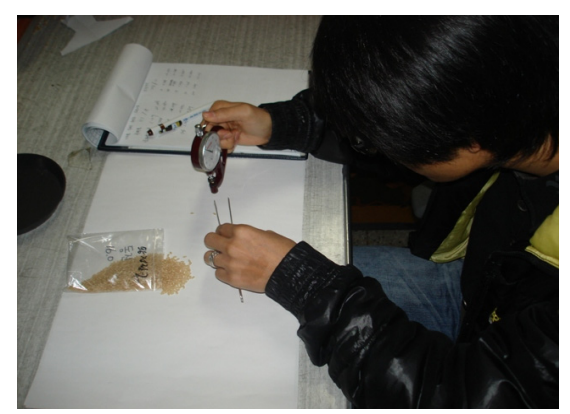

(e) Measurement of thickness

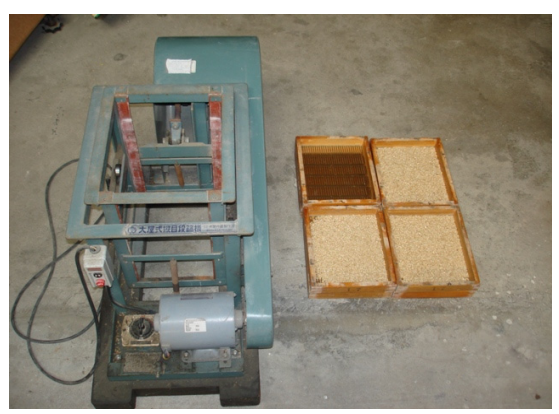

(c) Sorting by sieve separator

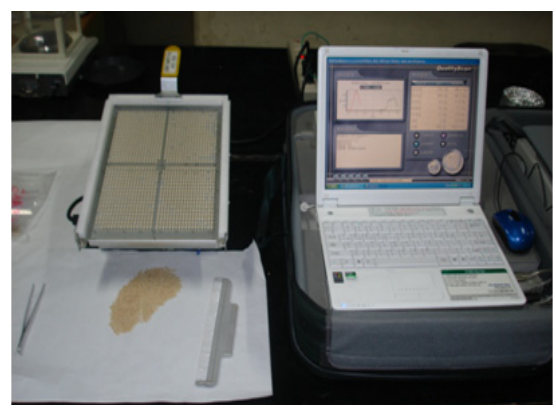

(f) Measurement of length and waith

Figure 1. Sorting process and measurement of the geometrical properties. 
with the air-oven method. $10 \pm 0.5$ grams of each sample was taken and dried in an experimental dryer (WFO600ND, TokyoRi-kakai, Japan) at a temperature of $135^{\circ} \mathrm{C}$ for 24 hours. Moisture content $\left(\mathrm{M}_{135}, \%\right)$ was determined from the ratio of the weight changes before and after drying. Then, the moisture content $\left(\mathrm{M}_{135}, \%\right)$ was changed into $105^{\circ} \mathrm{C}$ standard moisture content using the following Eq. (1) (Yon et al., 2001):

$$
M_{105}=100-1.012\left(100-M_{135}\right)
$$

\section{The correction of brown rice according to moisture content}

The difference in the initial and final moisture content on the brown rice varieties occurred during drying process. Therefore, in order to compare the length, width, and thickness by brown rice varieties, the correction equation was made using moisture content. The change in the shape factors were evaluated by correction moisture content changes at $18,17,16,15,14$ and $13 \%$.

\section{Results and discussion}

\section{The changes of length according to moisture content and varieties}

\section{Whole grain}

The changes of the length with moisture content are shown in Figure 2. In all kinds of brown rice varieties, there was decrease in the length with decreasing moisture content, and in the case of Il Pum, Chu Cheong, Dong Jin, and Nam Pyeong, the length decreased by a small margin after 15\% moisture content. The Dae An rice showed the highest grain length followed by Un Gwang and Dong Jin, while the shortest variety was observed in Chu Cheong.

The correction value of the length of whole grain is shown in Table 1. At 18\% moisture, the correction value of the length for Il Pum, Chu Cheong, Dong Jin, Un Gwang, Nam Pyeong, and Dae An variety were 5.026, 4.944, 5.172, 5.225, 5.026 and $5.320 \mathrm{~mm}$, respectively. These correspondingly decreased by $0.120,0.123,0.124,0.123$, 0.106 and $0.120 \mathrm{~mm}$ at $13 \%$ moisture content. The smallest change in length was observed in Nam Pyeong variety. Dae An variety, which had the longest grain length was $0.379,0.378,0.377 \mathrm{~mm}$ longer than the shortest grain (Chu Cheong variety) at the correction moisture content of 14,15 , and $16 \%$.

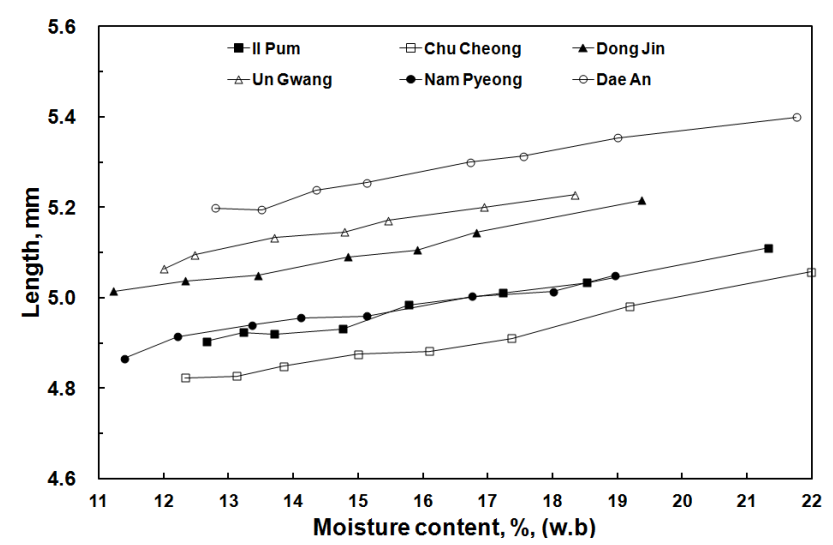

Figure 2. The variation in the length of whole grain according to moisture content and varieties.

Table 1. The correction of the length for whole grain according to moisture content and varieties

\begin{tabular}{|c|c|c|c|c|}
\hline \multicolumn{2}{|c|}{ Cultivars } & II Pum & Chu Cheong & Dong Jin \\
\hline \multicolumn{2}{|c|}{ Correction equation } & $Y=0.0239 X+4.5962$ & $Y=0.0245 X+4.5025$ & $Y=0.0247 X+4.7278$ \\
\hline \multicolumn{2}{|c|}{ Coefficient of determination $\left(R^{2}\right)$} & 0.982 & 0.974 & 0.981 \\
\hline \multirow{3}{*}{$\begin{array}{l}\text { Correction value } \\
\qquad(\mathrm{mm})\end{array}$} & $16 \%$ & 4.979 & 4.895 & 5.123 \\
\hline & $15 \%$ & 4.955 & 4.870 & 5.098 \\
\hline & $14 \%$ & 4.931 & 4.846 & 5.074 \\
\hline \multicolumn{2}{|c|}{ Cultivars } & Un Gwang & Nam Pyeong & Dae An \\
\hline \multicolumn{2}{|c|}{ Correction equation } & $Y=0.0245 X+4.7278$ & $Y=0.0211 X+4.7841$ & $Y=0.0239 X+4.8899$ \\
\hline \multicolumn{2}{|c|}{ Coefficient of determination $\left(R^{2}\right)$} & 0.975 & 0.958 & 0.982 \\
\hline \multirow{3}{*}{$\begin{array}{l}\text { Correction value } \\
(\mathrm{mm})\end{array}$} & $16 \%$ & 5.176 & 4.984 & 5.272 \\
\hline & $15 \%$ & 5.152 & 4.963 & 5.248 \\
\hline & $14 \%$ & 5.127 & 4.942 & 5.225 \\
\hline
\end{tabular}




\section{Unriped grain}

The variation in length according to moisture content of unriped grain is shown in Figure 3. As shown in Figure 3, Dae An variety showed the longest grain length, while no considerable difference between Dong Jin and Un Gwang variety length is shown. All unriped grain showed the same change trend in length of whole grain.

The correction value in the length of unriped grain is shown in Table 2. As shown in the table 2, the correction value for length in Il Pum, Chu Cheong, Dong Jin, Un Gwang, Nam Pyeong, and Dae An variety were 4.869, $4.833,5.057,5.070,4927$, and $5.245 \mathrm{~mm}$, respectively, at the $18 \%$ moisture content. These correspondingly decreased by $0.109,0.106,0.129,0.120,0.106$, and $0.101 \mathrm{~mm}$ at 13\% moisture content. Dong Jin variety showed the largest change in length. Dae An variety, likewise had the longest grain length, and it was at $0.373,0.415$ and 0.377

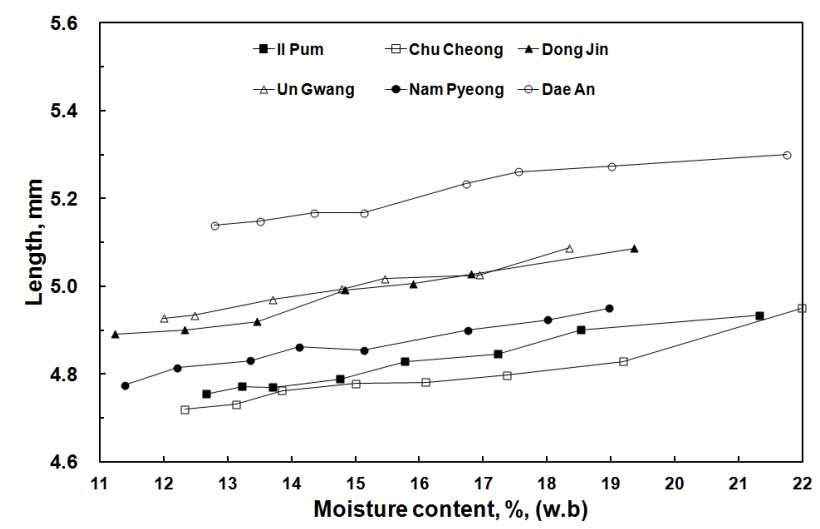

Figure 3. The variation in the length of unriped grain according to moisture content and varieties. $\mathrm{mm}$ longer than the shortest grain (Chu Cheong variety) at correction moisture content of 14,15 , and $16 \%$, respectively.

\section{Green dead rice}

The variation of the length of green dead rice according to moisture content is shown in Figure 4. The length of Green dead rice decreased in a linear trend for Dong Jin and Un Gwang variety. In the case of Il Pum, Chu Cheong, and Nam Pyeong variety, the length decreased by a small margin after 15\% moisture content was reached. In addition, the Chu Cheong variety showed the shortest grain length compared to the other varieties. Green dead rice of Dae An variety could not be measured, because it did not exist in the testing materials of Dae An variety.

The correction value for length of green dead rice is shown in Table 3. At 18\% moisture content, the correction

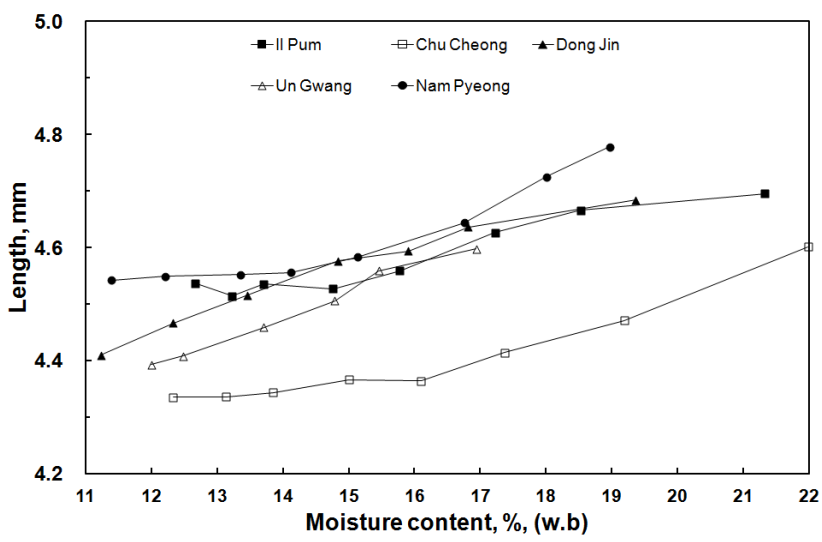

Figure 4. The variation in the length of dead green rice according to moisture content and varieties.

Table 2. The correction of the length of unriped grain according to moisture content and varieties

\begin{tabular}{|c|c|c|c|c|}
\hline \multicolumn{2}{|c|}{ Cultivars } & II Pum & Chu Cheong & Dong Jin \\
\hline \multicolumn{2}{|c|}{ Correction equation } & $Y=0.0218 X+4.477$ & $Y=0.0211 X+4.4532$ & $Y=0.0258 X+4.5921$ \\
\hline \multicolumn{2}{|c|}{ Coefficient of determination $\left(R^{2}\right)$} & 0.975 & 0.917 & 0.972 \\
\hline \multirow{3}{*}{$\begin{array}{l}\text { Correction value } \\
\qquad(\mathrm{mm})\end{array}$} & $16 \%$ & 4.826 & 4.791 & 5.005 \\
\hline & $15 \%$ & 4.804 & 4.770 & 4.979 \\
\hline & $14 \%$ & 4.782 & 4.749 & 4.953 \\
\hline \multicolumn{2}{|c|}{ Cultivars } & Un Gwang & Nam Pyeong & Dae An \\
\hline \multicolumn{2}{|c|}{ Correction equation } & $Y=0.024 X+4.6381$ & $Y=0.0211 X+4.5474$ & $Y=0.0202 X+4.8815$ \\
\hline \multicolumn{2}{|c|}{ Coefficient of determination $\left(\mathrm{R}^{2}\right)$} & 0.973 & 0.971 & 0.936 \\
\hline \multirow{3}{*}{$\begin{array}{l}\text { Correction value } \\
(\mathrm{mm})\end{array}$} & $16 \%$ & 5.022 & 4.885 & 5.205 \\
\hline & $15 \%$ & 4.998 & 4.864 & 5.185 \\
\hline & $14 \%$ & 4.974 & 4.843 & 5.164 \\
\hline
\end{tabular}




\begin{tabular}{|c|c|c|c|c|}
\hline \multicolumn{2}{|c|}{ Cultivars } & II Pum & Chu Cheong & Dong Jin \\
\hline \multicolumn{2}{|c|}{ Correction equation } & $Y=0.0225 X+4.2252$ & $Y=0.0294 X+3.9239$ & $Y=0.0340 X+4.0498$ \\
\hline \multicolumn{2}{|c|}{ Coefficient of determination $\left(R^{2}\right)$} & 0.913 & 0.934 & 0.967 \\
\hline \multirow{3}{*}{$\begin{array}{l}\text { Correction value } \\
\qquad(\mathrm{mm})\end{array}$} & $16 \%$ & 4.585 & 4.394 & 4.594 \\
\hline & $15 \%$ & 4.563 & 4.365 & 4.560 \\
\hline & $14 \%$ & 4.540 & 4.336 & 4.526 \\
\hline \multicolumn{2}{|c|}{ Cultivars } & Un Gwang & Nam Pyeong & Dae An \\
\hline \multicolumn{2}{|c|}{ Correction equation } & $Y=0.0436 X+3.866$ & $Y=0.0355 X+4.0763$ & - \\
\hline \multicolumn{2}{|c|}{ Coefficient of determination $\left(R^{2}\right)$} & 0.987 & 0.912 & - \\
\hline \multirow{3}{*}{$\begin{array}{l}\text { Correction value } \\
\qquad(\mathrm{mm})\end{array}$} & $16 \%$ & 4.564 & 4.644 & - \\
\hline & $15 \%$ & 4.520 & 4.609 & - \\
\hline & $14 \%$ & 4.476 & 4.573 & - \\
\hline
\end{tabular}

\begin{tabular}{|c|c|c|c|c|}
\hline \multicolumn{2}{|c|}{ Cultivars } & II Pum & Chu Cheong & Dong Jin \\
\hline \multicolumn{2}{|c|}{ Correction equation } & $Y=0.0218 X+4.477$ & $Y=0.0211 X+4.4532$ & $Y=0.0258 X+4.5921$ \\
\hline \multicolumn{2}{|c|}{ Coefficient of determination $\left(R^{2}\right)$} & 0.975 & 0.917 & 0.972 \\
\hline \multirow{3}{*}{$\begin{array}{l}\text { Correction value } \\
\qquad(\mathrm{mm})\end{array}$} & $16 \%$ & 4.826 & 4.791 & 5.005 \\
\hline & $15 \%$ & 4.804 & 4.770 & 4.979 \\
\hline & $14 \%$ & 4.782 & 4.749 & 4.953 \\
\hline \multicolumn{2}{|c|}{ Cultivars } & Un Gwang & Nam Pyeong & Dae An \\
\hline \multicolumn{2}{|c|}{ Correction equation } & $Y=0.024 X+4.6381$ & $Y=0.0211 X+4.5474$ & $Y=0.0202 X+4.8815$ \\
\hline \multicolumn{2}{|c|}{ Coefficient of determination $\left(R^{2}\right)$} & 0.973 & 0.971 & 0.936 \\
\hline \multirow{3}{*}{$\begin{array}{l}\text { Correction value } \\
\qquad(\mathrm{mm})\end{array}$} & $16 \%$ & 5.022 & 4.885 & 5.205 \\
\hline & $15 \%$ & 4.998 & 4.864 & 5.185 \\
\hline & $14 \%$ & 4.974 & 4.843 & 5.164 \\
\hline
\end{tabular}

value for length of Il Pum, Chu Cheong, Dong Jin, Un Gwang, and Nam Pyeong were 4.630, 4.453, 4.662, 4.65 and $4.715 \mathrm{~mm}$, respectively. These correspondingly decreased by $0.112,0.147,0.170,0.218$ and $0.177 \mathrm{~mm}$ at $13 \%$ moisture content. The largest change in length was observed among green dead rice of Un Gwang variety.

\section{The changes of width according to moisture content and varieties}

\section{Whole grain}

The changes of the width of whole grain according to moisture content is shown in Figure 5. The maximum and minimum width were observed in Il Pum and Dong Jin variety, respectively. The width linearly decreased with moisture content.

The correction value for width of whole grain rice is

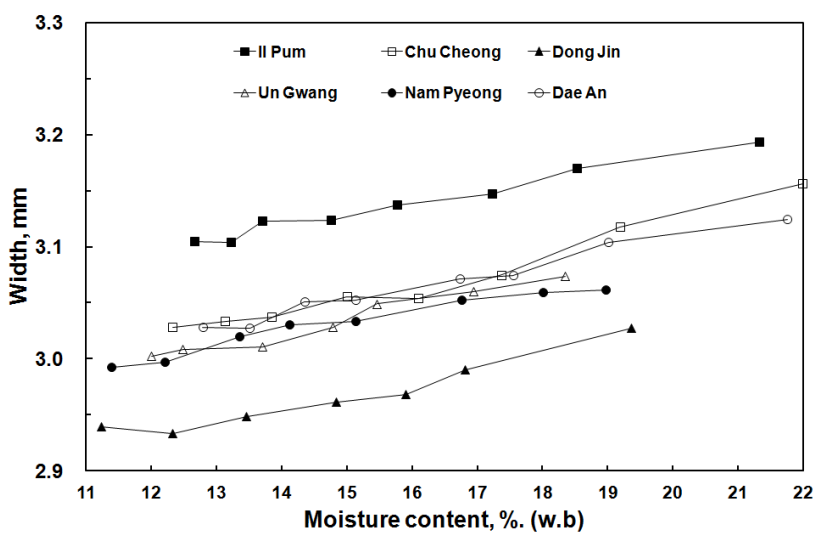

Figure 5. The variation in the width of whole grain according to moisture content and varieties.

shown in Table 4. As shown in the table 4, the correction value for width of Il Pum, Chu Cheong, Dong Jin, Un 
Gwang, Nam Pyeong, and Dae An variety were 3.159, $3.096,3.003,3.071,3.059$ and $3.096 \mathrm{~mm}$, respectively, at $18 \%$ moisture content. These values correspondingly decreased by $0.052,0.068,0.057,0.060,0.048$ and 0.057 $\mathrm{mm}$, respectively, at $13 \%$ moisture content. The width of Chu Cheong variety decreased by the largest margin. Furthermore, Il Pum variety with the largest grain registered $0.161,0.159,0.158 \mathrm{~mm}$ higher than that of the lowest Dong Jin at correction moisture content of 14, 15 and $16 \%$, respectively.

\section{Unriped grain}

Figure 6 shows the variation in the width of unriped grain according to moisture content. The Il Pum and Dong Jin variety showed the maximum and minimum width, respectively. The unriped grain showed the same change trend in width as shown in the whole grain that decreased

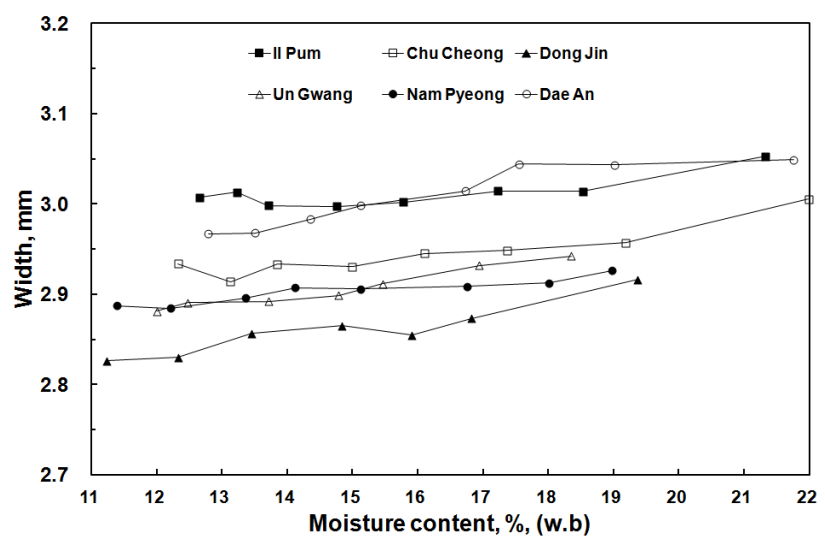

Figure 6. The variation in the width of unriped grain according to moisture content and varieties. linearly with moisture content.

Table 5 shows the correction value of the width of unriped grain. At 18\% moisture content, the correction value for the width of Pum, Chu Cheong, Dong Jin, Un Gwang, Nam Pyeong, and Dae An variety were 3.022, 2.960, 2.892, 2.937, 2.919 and $3.022 \mathrm{~mm}$ respectively, and decreased by $0.035,0.045,0.051,0.048,0.024$, and $0.051 \mathrm{~mm}$ at $13 \%$ moisture content respectively. The smallest change in width of unriped grain was shown in Nam Pyeong variety.

\section{Green dead rice}

The variation in the width of Green dead rice according to moisture content is shown in Figure 7. The maximum and minimum width were observed from Il Pum and Dong Jin variety, respectively.

Table 6 shows the correction value in the width of

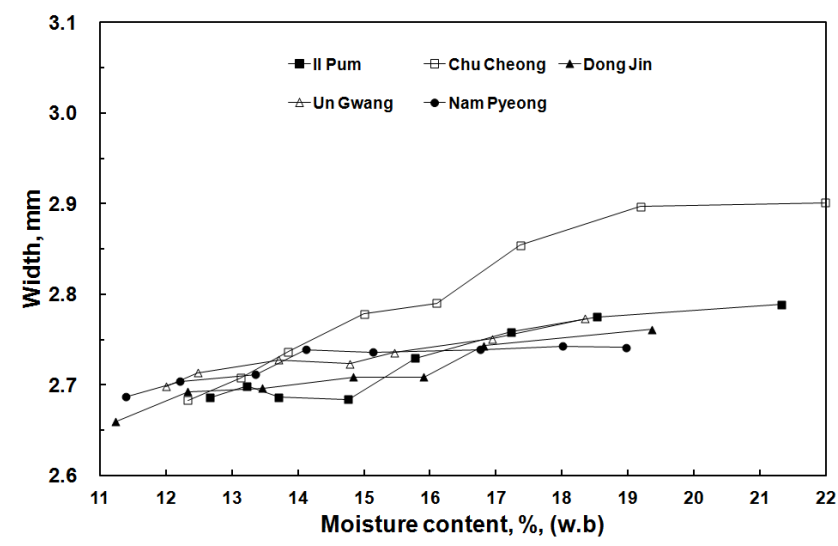

Figure 7. The variation in the width of dead green rice according to moisture content and varieties.

Table 5. The correction of the width of unriped according to moisture content and varieties

\begin{tabular}{|c|c|c|c|c|}
\hline \multicolumn{2}{|c|}{ Cultivars } & II Pum & Chu Cheong & Dong Jin \\
\hline \multicolumn{2}{|c|}{ Correction equation } & $Y=0.0218 X+4.477$ & $Y=0.0211 X+4.4532$ & $Y=0.0258 X+4.5921$ \\
\hline \multicolumn{2}{|c|}{ Coefficient of determination $\left(R^{2}\right)$} & 0.975 & 0.917 & 0.972 \\
\hline \multirow{3}{*}{$\begin{array}{l}\text { Correction value } \\
\qquad(\mathrm{mm})\end{array}$} & $16 \%$ & 4.826 & 4.791 & 5.005 \\
\hline & $15 \%$ & 4.804 & 4.770 & 4.979 \\
\hline & $14 \%$ & 4.782 & 4.749 & 4.953 \\
\hline \multicolumn{2}{|c|}{ Cultivars } & Un Gwang & Nam Pyeong & Dae An \\
\hline \multicolumn{2}{|c|}{ Correction equation } & $Y=0.024 X+4.6381$ & $Y=0.0211 X+4.5474$ & $Y=0.0202 X+4.8815$ \\
\hline \multicolumn{2}{|c|}{ Coefficient of determination $\left(\mathrm{R}^{2}\right)$} & 0.973 & 0.971 & 0.936 \\
\hline \multirow{3}{*}{$\begin{array}{l}\text { Correction value } \\
(\mathrm{mm})\end{array}$} & $16 \%$ & 5.022 & 4.885 & 5.205 \\
\hline & $15 \%$ & 4.998 & 4.864 & 5.185 \\
\hline & $14 \%$ & 4.974 & 4.843 & 5.164 \\
\hline
\end{tabular}




\begin{tabular}{|c|c|c|c|c|}
\hline \multicolumn{2}{|c|}{ Cultivars } & II Pum & Chu Cheong & Dong Jin \\
\hline \multicolumn{2}{|c|}{ Correction equation } & $Y=0.0225 X+4.2252$ & $Y=0.0294 X+3.9239$ & $Y=0.0340 X+4.0498$ \\
\hline \multicolumn{2}{|c|}{ Coefficient of determination $\left(\mathrm{R}^{2}\right)$} & 0.913 & 0.934 & 0.967 \\
\hline \multirow{3}{*}{$\begin{array}{l}\text { Correction value } \\
\qquad(\mathrm{mm})\end{array}$} & $16 \%$ & 4.585 & 4.394 & 4.594 \\
\hline & $15 \%$ & 4.563 & 4.365 & 4.560 \\
\hline & $14 \%$ & 4.540 & 4.336 & 4.526 \\
\hline \multicolumn{2}{|c|}{ Cultivars } & Un Gwang & Nam Pyeong & Dae An \\
\hline \multicolumn{2}{|c|}{ Correction equation } & $Y=0.0436 X+3.866$ & $Y=0.0355 X+4.0763$ & - \\
\hline \multicolumn{2}{|c|}{ Coefficient of determination $\left(R^{2}\right)$} & 0.987 & 0.912 & - \\
\hline \multirow{3}{*}{$\begin{array}{l}\text { Correction value } \\
\qquad(\mathrm{mm})\end{array}$} & $16 \%$ & 4.564 & 4.644 & - \\
\hline & $15 \%$ & 4.520 & 4.609 & - \\
\hline & $14 \%$ & 4.476 & 4.573 & - \\
\hline
\end{tabular}

\begin{tabular}{|c|c|c|c|c|}
\hline \multicolumn{2}{|c|}{ Cultivars } & II Pum & Chu Cheong & Dong Jin \\
\hline \multicolumn{2}{|c|}{ Correction equation } & $Y=0.0120 X+1.9767$ & $Y=0.0182 X+1.8162$ & $Y=0.0120 X+1.9032$ \\
\hline \multicolumn{2}{|c|}{ Coefficient of determination $\left(R^{2}\right)$} & 0.841 & 0.927 & 0.989 \\
\hline \multirow{3}{*}{$\begin{array}{l}\text { Correction value } \\
\qquad(\mathrm{mm})\end{array}$} & $16 \%$ & 2.169 & 2.107 & 2.095 \\
\hline & $15 \%$ & 2.157 & 2.089 & 2.083 \\
\hline & $14 \%$ & 2.145 & 2.071 & 2.071 \\
\hline \multicolumn{2}{|c|}{ Cultivars } & Un Gwang & Nam Pyeong & Dae An \\
\hline \multicolumn{2}{|c|}{ Correction equation } & $Y=0.0103 X+2.0197$ & $Y=0.0117 X+1.8864$ & $Y=0.0092 X+1.9572$ \\
\hline \multicolumn{2}{|c|}{ Coefficient of determination $\left(R^{2}\right)$} & 0.948 & 0.961 & 0.985 \\
\hline \multirow{3}{*}{$\begin{array}{l}\text { Correction value } \\
\qquad(\mathrm{mm})\end{array}$} & $16 \%$ & 2.185 & 2.074 & 2.104 \\
\hline & $15 \%$ & 2.174 & 2.062 & 2.095 \\
\hline & $14 \%$ & 2.164 & 2.050 & 2.086 \\
\hline
\end{tabular}

green dead rice. As seen in table 6, the correction value of the width for Il Pum, Chu Cheong, Dong Jin, Un Gwang, and Nam Pyeong variety were 2.784, 2.715, 2.621, 2.618, 2.644 and $3.096 \mathrm{~mm}$, respectively, at the moisture content of $18 \%$. These correspondingly decreased by $0.112,0.147$, $0.170,0.218$ and $0.177 \mathrm{~mm}$ at $13 \%$ moisture content. The largest change in width of green dead rice was shown in Un Gwang variety.

\section{The changes of thickness according to moisture content and varieties}

\section{Whole grain}

Figure 8 shows the variation in the thickness of whole grain according to moisture content and brown rice varieties. As shown in the Figure 8, Un Gwang variety observed the thickest while Nam Pyeong variety observed the thinnest in the testing materials.

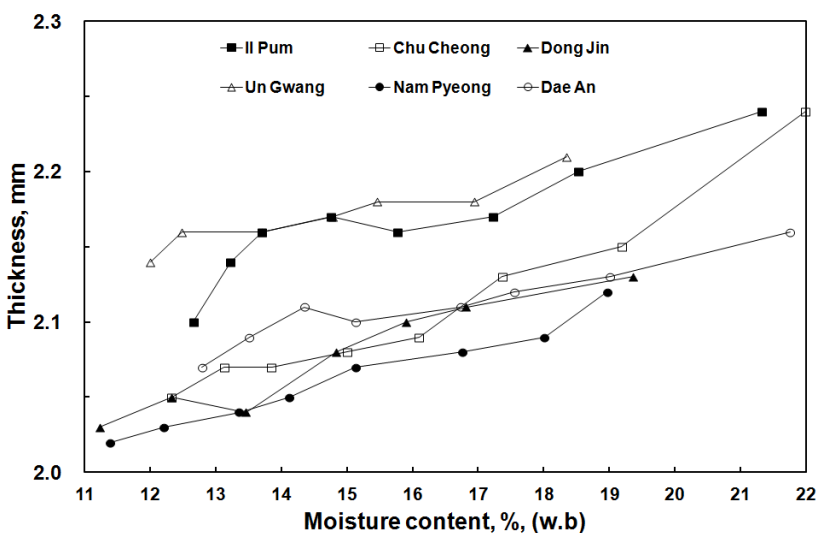

Figure 8. The variation in the thickness of whole grain according to moisture content and varieties.

In order to compare the changes of thickness of the different kinds of brown rice, the correction value for thickness of whole grain is shown in Table 7 . The largest 
decrement in thickness was observed in Chu Cheong variety. The correction value of the thickness for Il Pum, Chu Cheong, Dong Jin, Un Gwang, Nam Pyeong, and Dae An varieties were 2.193, 2.144, 2.119, 2.205, 2.097 and $2.123 \mathrm{~mm}$, respectively, at moisture content of $18 \%$, and decreased by $0.060,0.091,0.060,0.052,0.059$ and 0.046 $\mathrm{mm}$ at $13 \%$ moisture content. The thickness of the Un Gwang variety was $0.114,0.112,0.111 \mathrm{~mm}$ thicker than the thinnest Nam Pyeong variety at the correction moisture content of 14,15 and $16 \%$, respectively.

\section{Unriped grain}

The variation in the thickness of unriped grain according to moisture content is shown in Figure 9. The Un Gwang and Nam Pyeong variety showed the maximum and minimum width, respectively.

Table 8 shows the correction value in the thickness of

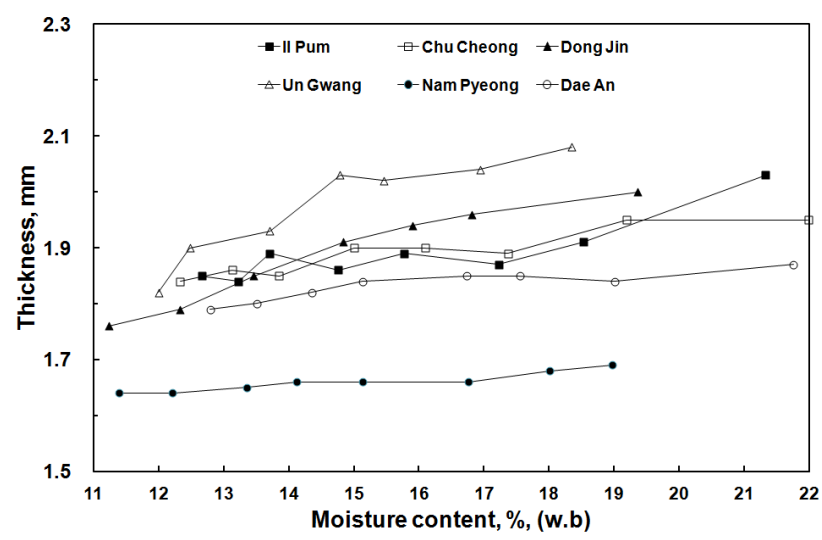

Figure 9. The variation in the thickness of unriped grain according to moisture content and varieties. unriped grain. The minimum and maximum decrement in thickness were observed from Nam Pyeong and Dae An variety, respectively. At $18 \%$ moisture content, the correction value for thickness of Il Pum, Chu Cheong, Dong Jin, Un Gwang, Nam Pyeong, and Dae An variety were $1.935,1.913,1.984,2.104,1.679,1.844 \mathrm{~mm}$, respectively and correspondingly decreased by $0.099,0.061,0.051$, $0.152,0.030$, and $0.038 \mathrm{~mm}$ at $13 \%$ moisture content. Un Gwang variety had the thickest grain at $0.266,0.305$ and $0.346 \mathrm{~mm}$ thicker than the thinnest Nam Pyeong variety at the correction moisture content of 14,15 and $16 \%$, respectively.

\section{Green dead rice}

Figure 10 shows the variation in the thickness of green dead rice according to moisture content and brown rice varieties. The maximum and minimum thickness were

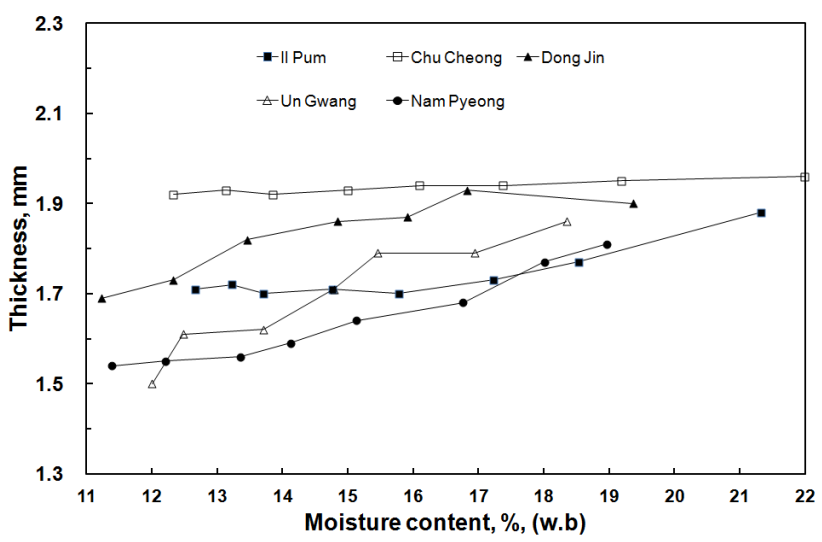

Figure 10. The variation in the thickness of green dead rice according to moisture content and varieties.

Table 8. The correction of the thickness of unriped grain according to moisture content and varieties

\begin{tabular}{|c|c|c|c|c|}
\hline \multicolumn{2}{|c|}{ Cultivars } & II Pum & Chu Cheong & Dong Jin \\
\hline \multicolumn{2}{|c|}{ Correction equation } & $Y=0.0198 X+1.579$ & $Y=0.0122 X+1.6937$ & $Y=0.0304 X+1.4369$ \\
\hline \multicolumn{2}{|c|}{ Coefficient of determination $\left(R^{2}\right)$} & 0.909 & 0.842 & 0.944 \\
\hline \multirow{3}{*}{$\begin{array}{l}\text { Correction value } \\
\qquad(\mathrm{mm})\end{array}$} & $16 \%$ & 1.896 & 1.889 & 1.923 \\
\hline & $15 \%$ & 1.876 & 1.877 & 1.893 \\
\hline & $14 \%$ & 1.856 & 1.865 & 1.863 \\
\hline \multicolumn{2}{|c|}{ Cultivars } & Un Gwang & Nam Pyeong & Dae An \\
\hline \multicolumn{2}{|c|}{ Correction equation } & $Y=0.0458 X+1.2794$ & $Y=0.0060 X+1.571$ & $Y=0.0076 X+1.7075$ \\
\hline \multicolumn{2}{|c|}{ Coefficient of determination $\left(R^{2}\right)$} & 0.737 & 0.963 & 0.757 \\
\hline \multirow{3}{*}{$\begin{array}{l}\text { Correction value } \\
\qquad(\mathrm{mm})\end{array}$} & $16 \%$ & 2.012 & 1.667 & 1.829 \\
\hline & $15 \%$ & 1.966 & 1.661 & 1.822 \\
\hline & $14 \%$ & 1.921 & 1.655 & 1.814 \\
\hline
\end{tabular}




\begin{tabular}{|c|c|c|c|c|}
\hline \multicolumn{2}{|c|}{ Cultivars } & II Pum & Chu Cheong & Dong Jin \\
\hline \multicolumn{2}{|c|}{ Correction equation } & $Y=0.0235 X+1.3509$ & $Y=0.0038 X+1.8769$ & $Y=0.0409 X+1.2396$ \\
\hline \multicolumn{2}{|c|}{ Coefficient of determination $\left(R^{2}\right)$} & 0.879 & 0.890 & 0.962 \\
\hline \multirow{3}{*}{$\begin{array}{l}\text { Correction value } \\
\qquad(\mathrm{mm})\end{array}$} & $16 \%$ & 1.727 & 1.938 & 1.894 \\
\hline & $15 \%$ & 1.703 & 1.934 & 1.853 \\
\hline & $14 \%$ & 1.680 & 1.930 & 1.812 \\
\hline \multicolumn{2}{|c|}{ Cultivars } & Un Gwang & Nam Pyeong & Dae An \\
\hline \multicolumn{2}{|c|}{ Correction equation } & $Y=0.0524 X+0.9234$ & $Y=0.0371 X+1.0845$ & - \\
\hline \multicolumn{2}{|c|}{ Coefficient of determination $\left(\mathrm{R}^{2}\right)$} & 0.906 & 0.950 & - \\
\hline \multirow{3}{*}{$\begin{array}{l}\text { Correction value } \\
\qquad(\mathrm{mm})\end{array}$} & $16 \%$ & 1.762 & 1.678 & - \\
\hline & $15 \%$ & 1.709 & 1.641 & - \\
\hline & $14 \%$ & 1.657 & 1.604 & - \\
\hline
\end{tabular}

observed by Chu Cheong and Nam Pyeong variety, and Chu Cheong variety showed the largest decrement in thickness.

The correction value of the thickness of green dead rice is shown in Table 9. As shown in Table 9, the correction value for the thickness of Il Pum, Chu Cheong, Dong Jin, Un Gwang and Nam Pyeong variety were 1.774, 1.945, 1.976, 1.876 and $1.752 \mathrm{~mm}$, respectively at $18 \%$ moisture content. These correspondingly decreased by 0.118 , $0.019,0.205,0.262$ and $0.186 \mathrm{~mm}$ at moisture content of $13 \%$. Chu Cheong variety showed the thickest at 0.326 , 0.293 and $0.260 \mathrm{~mm}$ thicker than the thinnest Nam Pyeong variety at the correction moisture content of 14 , 15 and $16 \%$, respectively.

\section{Conclusions}

This study was conducted to optimize the sorting factors and establish an efficient sorting technology for brown rice. After hulling of the main paddy variaties cultivated in Korea, the geometrical properties were studied, determine the optimal sorting factors. The brown rice varieties used in this study were Il Pum, Chu Cheong, Dong Jin, Un Gwang, Nam Pyeong, and Dae An. These were classified into whole grain, unriped grain, and green dead rice. The shape factors were analyzed based on length, width and thickness of the grains. Conclusions of the study are as follows:

(1) The maximum and minimum length in whole grain, unriped grain and green dead rice were observed Dae An and Chu Cheong variety. Especially, in the case of whole grain and unriped grain, Dae An variety, which had the longest grains were 0.379 and $0.373,0.378$ and $0.415,0.377$ and 0.377 $\mathrm{mm}$ longer than the shortest Chu Cheong variety at correction moisture content of 14,15 and $16 \%$, respectively.

(2) The Il Pum variety showed the maximum width while Dong Jin variety showed the minimum width.

(3) In the case of thickness, the maximum and minimum thickness were observed in Un Gwang and Nam Pyeong variety for the whole grain and unriped grain, respectively. The whole grain thickness of Un Gwang variety was $0.114,0.112,0.111 \mathrm{~mm}$ thicker than the Nam Pyeong variety at the correction moisture content of 14,15 and $16 \%$, respectively. For the unriped grain, the Un Gwang variety was $0.266,0.305$ and $0.346 \mathrm{~mm}$ thicker than Nam Pyeong variety. In the case of green dead rice, Chu Cheong variety, which showed the thickest was $0.326,0.293$ and $0.260 \mathrm{~mm}$ thicker than the thinnest of Nam Pyeong variety at the correction moisture content of 14,15 and $16 \%$, respectively.

(4) For different of the brown rice varieties, the length and width of whole grain and unriped grain had $0.2 \sim 0.4 \mathrm{~mm}$ of difference from green dead rice. Therefore, the length and width can be used as sorting factors of whole grain and green dead rice.

(5) The length and width, which showed $0.1 \mathrm{~mm}$ differences are considered inappropriate as sorting factors for whole grain and unriped grain. However, in the thickness showed $0.2 \sim 0.4 \mathrm{~mm}$ difference 
between whole grain and unriped grain, and therefore can be considered as optimum sorting factor of whole grain and unriped grin.

\section{Conflict of Interest}

No potential conflict of interest relevant to this article was reported.

\section{Acknowledgement}

We would like to extend our appreciation to the Korea Institute of Planning \& Evaluation for Technology in Food, Agriculture, Forestry \& Fisheries for their financial support and for encouraging us to attempt this study in 2009.

\section{References}

Bughio, F. M., and R. M. Wilkins. 2004. Influence of malathion resistance status on survival and growth of Tribolium castaneum (Coleoptera:Tenebrionidae), when fed on flour from insect-resistant and susceptible grain rice cultivars. The Journal of the stored Products Research. 40:65-75.

Choung, J. I., U. C. Song, J. H. Cho, N. B. Park, J. Y. Lee, S. Y. Kim, J. R. Kang, J. C. Ko and K. Y. Ha. 2008. Adaptability of whole crop silage rice followed after rye cultivation in alpine area. The Korean Society of International Agriculture. 20(4):336-340. (In Korean)

Han, C. S., K. S. Yon, T. H. Kang, H. Y. Jeon, H. K. Koh, J. D. So and D. B. Song. 2001. Study on the conditioning of brown rice (I)-Property variation and predicted model of brown rice after conditioning-. Journal of Biosystems Engineering 26(1):39-46. (In Korean)

Kawata, M., S. Harada, B. Antonio and K. Oono. 1992. Protoclonal variation of plant regeneration in rice. Tissue and Organ Culture. 28:1-10.

Kim, H., D. C. Kim, S. E. Lee and O. W. Kim. 2009. Milling characteristics of milled rice according to milling ratio of friction and abrasive milling. Journal of Biosystems Engineering 34(6):439-445. (In Korean)

Kim, K. J., S. L. Kim, J. Song, J. R. Son, H. G. Hwang, J. C. Shin, H. C. Choi, Y. K. Choi and Y. K. Min. 2001. Physicochemical and milling characteristics of paddy rice with the harvesting times. Journal of the Korean Society for Applied Biological Chemistry. 44(3):179184. (In Korean)

Lee, Y. H. 2010. Rice growth and grain quality in no-till and organic farming paddy field as affected by different rice cultivars. Korean Journal of Soil Science and fertilizer. 43(2):209-216. (In Korean)

Park, C. E., Y. S. Kim, D. J. Park, K. J. Park and B. K. Kim. 2011. Pasting and sensory properties of commercial rice products. Korean Journal of Food Science and Technology. 43(4):401-406. (In Korean)

Yon, K. S., C. S. Han and S. C. Cho. 2001. Milling Characteristics of Vertical Small Scale Milling Machine for the Rough Rice. Journal of Biosystems Engineering. 26(2):177-188. (In Korean)

Yoon, S. T., J. H. Kim and H. Y. Kim. 2005. Study on the arrangement of high-yielding rice varieties for North Korea's climate. The Korean Society of International Agriculture. 17(4):243-251. (In Korean) 